\title{
What Does Affect Theory Do? Or, How to Pay Attention to the Possibilities of Attending
}

\begin{abstract}
The present paper explores the role of affect theory in social and political critique, specifically in terms of how it relates to modes of attending in the context of theorizing. In this regard, I examine why affect theory has markedly reshaped the contours of social and political academic discourse in recent decades, and what alternatives to theorizing it introduces or enables new openings to. In order to answer these questions, I delve into the works of various scholars who use affect theory as a framework for theorizing. I posit that engaging in an affective mode of attending enables attention to structures of bifurcation rather than binaries, by conceptualizing theory in terms of beside-ness rather than beyond-ness. In doing so, I aim to shed light on what an affective mode of attending might be, and what affect theory can teach us about what it means to attend, or how to engage in alternative attendings. I conclude the paper with a consideration of the 'So what?' question-in other words, why is the attention to attending significant? By attending to the possibilities inherent in alternative attendings, affect theory illuminates that there need not be 'outside-ness' understood in the sense of 'beyond-ness' for there to be an outside in the sense of an alternative. To attend to something from a different stance, which then conditions different contours for the possibilities enabled from that stance, means that there exist multiple 'outsides' from within the supposed 'inside'.
\end{abstract}

KEYWORDS: Affect theory, attention, modes of attending

a

Introduction

What does affect theory do? I begin with this question to examine why affect theory has markedly reshaped the contours of social and political academic discourse in recent decades. In other words: Why affect theory, and why now? What does affect theory do differently, if anything? What alternatives to theorizing does it introduce or enable new openings to? By delving into the works of various scholars who use 
affect theory as a framework for modes of critique, I aim to illuminate what an affective mode of attending might be, and what affect theory can teach us about what it means to attend, or how to engage in alternative attendings.

I begin with a brief foray into the psychology of attention, in order to understand how the psychological phenomenon of attention is related to knowledge production. In this regard, I ask: How does our understanding of how we can and do attend illuminate to us the importance of considering what it is we attend to when we produce knowledge in social and political thought? In this vein, I suggest that affect theory involves a particular mode of attending within the realm of knowledge production, one that enables and reinforces a specific theoretical framework from which to approach critique. In doing so, I suggest that attending is neither universal nor neutral; thus, the ways in which we choose to attend shape the contours of the possibilities of knowledge we may produce. Two main questions then emerge: (i) What kind of knowledge does affect theory, as a theoretical framework, enable? (ii) What are the ethics of attending, specifically in the realm of knowledge production? I spend the majority of the present paper focusing on the first question by engaging in a survey of various scholars whose works incorporate an affective mode of attending. In doing so, I hope to excavate an answer to the overarching question that marks the opening of this paper: "What does affect theory do?" More specifically, what does affect theory do with respect to attention?

I posit that engaging in an affective mode of attending enables attention to structures of bifurcation rather than binaries, by conceptualizing theory in terms of besideness rather than beyond-ness. Firstly, I look at the works of Melissa Gregg and Eve Sedgwick - The Affect Theory Reader and Touching Feeling, respectively — which both speak of affect as a positionality of 'beside-ness'. I move deeper into affect theory by considering how a positionality of 'beside-ness' rather than 'beyond-ness' implicates the structure of the binary in theorizing. In this vein, I look at how the relationship between interiority and exteriority, specifically with respect to subjectivity, is affectively - and perhaps effectively — re-imagined in the realms of touch and sovereignty. Under the subheading "Affective Attending Re-thinks Subjectivity by Re-configuring the Structure of Interiority/Exteriority", I look at how Judith Butler (Senses of the Subject) has troubled understandings of subjectivity that are heavily grounded in the notion of interiority by illuminating the role of the affectability of bodies to exteriority through the touch. Under the same subheading, I use Elizabeth Lorey's State of Insecurity to highlight the importance of socio-political contexts on modes of attending, and, conversely, how the ways in which we choose to attend affect the ways in which we interpret our context and the kinds of knowledge production about it that ensue.

I conclude the paper with a consideration of the 'So what?' question-in other words, why is the attention to attending significant? In recent turns within the realm of social and political theorizing, the atmosphere seems to have been rife 
with anxiety about the impossibility of an 'outside' or a 'beyond' —an issue that has undoubtedly been spurred by the teleological and totalizational nature of much of the history and philosophy of social and political thought. By attending to the possibilities inherent in alternative attendings, affect theory illuminates that there need not be 'outside-ness' understood in the sense of 'beyond-ness' for there to be an outside in the sense of an alternative. To attend to something from a different stance, which then conditions different contours for the possibilities enabled from that stance, means that there exists multiple 'outsides' from within the supposed 'inside'.

\section{To Attend or Not to Attend?}

What does it mean to attend? Let us begin with one of the founders of modern psychology, William James. This is precisely how Wayne Wu embarks on his project in Attention, an interdisciplinary philosophical and psychological treatise on the topic wherein he "hope[s] to underscore the philosophical importance of attention"1. In his opening pages, Wu defines attention, via James, as "the taking possession by the mind, in clear and vivid form, of one out of what seem several simultaneously possible objects or trains of thought. Focalization, concentration, of consciousness are of its essence. It implies withdrawal from some things in order to deal effectively with others" ${ }^{2}$. This initial exposition tells us that attention operates by highlighting an object out of the possibility of many, at the expense of these other many. As $\mathrm{Wu}$ restates in the final pages of Attention, "[a]ttention is by most accounts a selective psychological capacity" ${ }^{3}$. We must wonder, then, what the implications are of such a process of selection, specifically in terms of the metaphysical question of consciousness.

In the present paper, I focus my analysis on how attending to the phenomenon of attention can be useful with respect to exploring the ways in which we choose to attend when producing knowledge in the realms of social and political thought. Wu sums up his project by stating that

"[a] central theme of this book is that attention is of rich philosophical significance, and if the current discussion points in the right direction, then attention is of great significance to theories of content. A major project will be to formulate theories of perceptual content with an eye towards the fact that we are creatures of (shifting) attention, and that how we attend can have striking modulations on how things appear to $\mathrm{us}^{\text {"4. }}$.

With this in mind, I provoke the reader to ask: What are the implications of intending to attend in particular ways, which simultaneously means intending to not attend in others? What modes of attending in critique enable what kinds of theoretical frameworks to emerge? Specifically, what "special way of thinking about the world" does affect theory enable? 


\section{Affective Modes of Attending}

Through my journeying into scholarship that has been affected by the touch of affect theory, I aim to show that it is not only what we pay attention to that matters in critique, but how we pay attention it. The scholarship that I survey throughout the present paper all engages in the task of taking on particular conceptual content in social and political academic discourse and finding new ports of entry into it-ones that don't move 'beyond' other forms of critique, but rather ones that stand 'beside', thereby opening up space for alternative attendings.

\section{i) Affect Attends 'Beside' Rather Than 'Beyond'}

In both The Affect Theory Reader and Touching Feeling, Melissa Gregg and Eve Sedgwick, respectively, speak of affect as 'beside-ness'. In her introduction to the Reader, Gregg describes affect as that which is "born in in-between-ness and resides as accumulative beside-ness" ${ }^{6}$. In her opening sentences of Touching Feeling, Sedgwick describes the book as "a project to explore promising tools and techniques for nondualistic thought and pedagogy" . Furthermore, "[a] lot of voices tell us to think nondualistically, and even what to think in that fashion. Fewer are able to transmit how to go about it, the cognitive and even affective habits and practices involved, which are less than amenable to being couched in prescriptive forms" Sedgwick goes on to attribute "a sense of possibility" to "new" 10 and "unarticulated"11 approaches. I argue that it is this kind of alternative attending in critique that puts us in touch with the 'how' of theorizing, while still keeping our feet firmly grounded in the 'what'. In other words, what questions we intend to attend to are affected by how we intend to attend to these questions - a how-ness that I posit is grounded in the attentive stance we have chosen to take, and one which will shape the contours of our asking.

Let us now turn to the question of 'beside-ness':

...what has been even more difficult is to get a little distance from beyond, in particular the bossy gesture of 'calling for' an imminently perfected critical or revolutionary practice that one can oneself only adumbrate.

Instead, as its title suggests, the most salient preposition in Touching Feeling is probably beside. Invoking a Deleuzian interest in planar relations, the irreducibly spatial positionality of beside also seems to offer some useful resistance to the ease with which beneath and beyond turn from spatial descriptors into implicit narratives of, respectively, origin and telos. ${ }^{12}$

Here, we can turn to the question of 'space' and its role in affect theory. As Sedgwick articulates in her introduction to Touching Feeling, affect theory's promise and potential lies in its attention to spatiality. Sedgwick juxtaposes the spatiality of 'beside-ness' with the temporality of 'beyond-ness', drawing a connection by inferring that the orientation of theoretical critique toward temporality is responsible 
for the teleological foundations on which current theorizing rests. On the other hand, 'beside-ness' can offer an alternative mode of attending, a new point of entry into critique - and perhaps one that we so desperately need in order to escape the Nietzschean cycle of eternal recurrence which temporal teleology has us believe there is no way out of, no way 'beyond'.

Such an attentive stance aims to construct affect not as a new mode of critique that moves us 'beyond' existing ones that are now meant to be viewed as obsolete, but rather to position affect as 'beside' current modes of critique which may be lacking due to their polarization. On this issue, we can engage with Kathleen Stewart's Ordinary Affects with respect to the notion of 'beside-ness' that is characteristic of the affective stance:

At once abstract and concrete, ordinary affects are more directly compelling than ideologies, and more fractious, multiplicitous, and unpredictable than symbolic meanings. They are not the kind of analytic object that can be laid out on a single, static plane of analysis and they don't lend themselves to a perfect, three-tiered parallelism between analytic subject, concept, and world. They are, instead, a problem or question emergent in disparate scenes and incommensurate forms and registers. A tangle of potential connections. ${ }^{13}$

In other words, because affect is grounded in singularity while simultaneously being open to the infinite possibility of potential connections, it has the ability to straddle both the abstract and the concrete. In this way, the touch of affect can burst through the containing walls of totalizing frameworks and expose them to the open space where the thought is vulnerable to being affected by the touch, where risk and surprise hold sway over the word. Stewart describes this process as creating "a contact zone for analysis" ${ }^{14}$, where this entails "pointing always outward to an ordinary world whose forms of living are now being composed and suffered, rather than seeking the closure or clarity of a book's interiority or riding a great rush of signs to a satisfying end" 15 . This leads one to ask: Does affect's 'beside-ness' simultaneously entail an 'outside-ness'?

ii) Affective Attending Re-thinks Subjectivity by Re-configuring the Structure of Interiority/Exteriority: Touch

Judith Butler's Senses of the Subject sheds light on the question of 'outside-ness' in affect theory and helps us to think through its implications for theorizing. In this recent work, Butler focuses on how the touch implicates the constitution of the 'I'. In her conceptualization of the ' $\mathrm{I}$ ' that is formed through the touch, Butler conceives of exteriority, or alterity, as prior to the interiority of the 'I'. In her own words, "... when we speak about subject formation, we invariably presume a threshold of susceptibility or impressionability that may be said to precede the formation of a conscious and deliberate ' $\mathrm{I}$ '. That means only that this creature that I am is affected by something outside of itself, understood as prior, that activates and informs the subject that I 
am." ${ }^{16}$. If we were to relate this notion of affection as that which is prior to the 'I' to our previous discussions of affect as residing in 'beside-ness' and now 'outsideness', we would infer that affect is that which stands 'beside' only insofar as this 'beside-ness' is understood simultaneously as a 'before' and an 'outside'. However, the 'before-ness' of affect is not temporally linear in the way that the term would suggest: "The task is to think of being acted on and acting as simultaneous, and not only as a sequence ... I am not formed once and definitively, but continuously or repeatedly" ${ }^{\prime 1}$. Here, Butler refers to her theory of performativity and repetition to conceptualize the constitution of the self through affect as an infinite circle that moves continuously through 'interiority' and 'exteriority' in such a way that one sphere cannot be conceived of without the other, rather than a linear path that begins with 'exteriority' and moves forward to 'interiority'.

Furthermore, if it is the affecting touch that brings the 'I' into being, then this must complicate the relationship between the immanence of affect and the representational character of discourse. That is, if "I am already affected before I can say 'I"'18, and simultaneously "that I have to be affected to say 'I' at all"19, then this 'I' that exists in the sphere of discourse could have only entered that sphere after having already been touched. This form of interdependence between the discursive 'I' and the touch which enables the possibility of its constitution can be seen as exemplary of the 'beside-ness' that affect theory occupies. The touch and the word cannot exist without one another, just as interior and exterior constitute each other-so much so, that for the 'I' to cut itself off from alterity, by engaging in a mode of being which only attends to the representational and the symbolic, would be to "engage in a form of disavowal that seeks to wish away primary and enduring modes of dependency and interdependency" ${ }^{20}$. Stated otherwise, "self-affirmation means affirming the world without which the self would not be"21. And the only way to affirm this world is to be open to being undone by it, to the ways in which its affecting touch breaks through the notions of "self-sovereignty" 22 and "sovereign individualism" 23 that our representational frameworks have erected-seemingly so concretely, yet in fact built with the "brittle" 24 material of "denial"25.

Does beginning critique with the touch of affect entail that affect simply 'supplements' representation and signification? Or, since, as Butler shows us, the trajectory is not a linear one, does beginning with the touch re-configure what the sphere of representation might look like? What would it mean to attend in a way that reconfigures critique as 'beside-ness'? Moreover, when we consider that 'before-ness', 'outside-ness' and 'beside-ness' all entail a spatial and temporal elsewhere, what does this tell us about where we are in the present moment of critique? With regard to the 'elsewhere-ness' that affect theory initiates, we have thus far determined that this elsewhere does not take the form of 'beyond-ness', but rather of 'beside-ness'. That is, the 'elsewhere-ness' of affect theory does not seek to establish a new domain of critique from which theorizing will now commence in an improved fashion, on a teleological path toward development. Rather, this elsewhere-ness is spatial in its 
re-positioning of the attentive stance from which to approach critique. From such a stance, one is able to re-configure what the sphere of representation might look like through the creation of new possibilities by choosing to attend differently-i.e. alternative attendings.

iii) Affective Attending Re-thinks Subjectivity by Re-configuring the Structure of Interiority/Exteriority: Sovereignty

In Judith Butler's Foreword to State of Insecurity, Butler highlights that Isabell Lorey takes on the issue of precarity in a way that "involves a rethinking of the doctrine of sovereignty, offering an important reformulation of Agamben's recent views on the sovereign exception" ${ }^{26}$. Since the notion of sovereignty "depends on the presumption that one's person or property is perpetually threatened by the outside, ... the exercise of sovereignty thus consists in a demand for security" ${ }^{27}$. From these opening statements, we can glean what Lorey aims to achieve in the following pages, which is to say a re-configuration of the notion of sovereignty that forces us to re-think the often unquestioned presumption that 'the outside' (exteriority, the other) is viewed as a threat to 'the inside' (interiority, the self), which must be secured against such danger. In Butler's terms, "Lorey asks us to think about the alternatives to accepting fear and insecurity as the basis for a political mobilization" ${ }^{28}$. In doing so, Lorey enables an awareness of how a taken-for-granted notion of sovereignty and the mode of attending it delineates and delimits might be made to be otherwise - not an otherwise that is 'beyond' it, but an otherwise that is 'beside' it. And yet, not a beside-ness that necessarily co-exists with the original mode of attending, but rather a beside-ness that dislocates and decentres it, in such a way as to make space for alternative modes of attending.

Let us begin with a definition of the term 'precarious' as used in Lorey's work: "The conceptual composition of 'precarious' can be described in the broadest sense as insecurity and vulnerability, destabilization and endangerment" ${ }^{29}$. Attending to this notion of precariousness while being grounded in the conceptual and sociopolitical context of sovereignty would thus illuminate the structure of an 'inside' that is threatened by an 'outside'. Alternatively, Lorey would like us to attend to the notion of precariousness from an existential stance, by referring to Butler's work on precariousness in Frames of $\mathrm{War}^{30}$. Attending to the notion of precariousness from the 'starting-point' — or the situated stance — of existence rather than sovereignty re-shapes the contours of what this mode of attending might look like, entail, and implicate. What would be the implications of responding to precariousness from this alternative mode of attending? Lorey uses the rest of the text to paint a picture of what this might look like, and how it has taken shape in particular instances.

Firstly, when precariousness is perceived through the lens of existence rather than that of sovereignty, "what is problematized here is not what makes everyone the same, but rather what is shared by all. Precariousness that is shared by all can also be understood as a separating factor: on the one hand it is what we all have in 
common, but on the other it is what distinguishes and separates us from others"31. We can thus immediately see how the concept of identity has shifted in this mode of attending, where sameness and difference are not structured as a binary, but rather where 'sharing' is a bifurcation/dualization of a simultaneous 'commonality' and 'separation'. This posits bifurcation as an alternative structure to the binary. The notion of bifurcation/dualization does not move us 'beyond' the structure of the binary, however; the 'bi-' and 'du-' prefixes are a clear indication of that. Rather, bifurcation/dualization can be viewed as dislocating the structure of the binary.

Moreover, "[a]s that which is shared, which is at once divisive and connective, precariousness denotes a relational difference, a shared differentness" 32 . To be at once one thing and yet another that is considered its binary opposite is to displace that binary structure- not the kind of displacement which destroys, but the kind that forces us to perceive the two elements in question from a different angle, from a different mode of attending. In this case, the 'at once' signifies a spatio-temporally shifted mode of attending, where time and space take on a different meaning with regards to the structure of the binary, since one cannot be both one thing and its opposing other. This therefore entails that the relation of sameness versus difference has shifted, where "precariousness denotes a relational difference, a shared differentness" ${ }^{33}$. A differentness that is shared is then not the kind of differentness which divides and separates - self from other, interior from exterior - but a different kind of differentness. What kind of differentness is it?

In a loop that takes us back to the question of beside-ness, Lorey's final chapter, "Exodus and Constituting", explores what it would mean to "[move] away from the dominant model of being limited and threatened by others" ${ }^{34}$. In doing so, Lorey affirms that 'moving away' is not 'moving beyond', to "a completely new place where living together is reinvented" 35 . Rather, 'moving away' for Lorey entails "emphasizing the potentiality and movement of exodus within power relations themselves, their reversal and the flight from them that is always possible, but never leads to an outside of power" ${ }^{36}$. Let us now ask again: What kind of differentness is it? If it is the kind that is not 'beyond', that does not destroy and create anew, but that decentres and dislocates, then is it the kind that is to be found in the Deleuzian fold ${ }^{37}$, where sameness and differentness are effects, doublings and contortions of each other? Is then a spatial mode of attending our opening into not only a displacement/decentering of critical perspective, but also of critical sensibility? If so, then how do we make space for space? Is it through the touch?

\section{Conclusion:What Affect Theory Does}

With regard to the question that this paper has endeavoured to address- "What does affect theory do?"-I have embarked on the exploration by asking what kinds of knowledges emerge from an affective stance of attending. I hope to have shown that affective modes of attending enable theoretical frameworks that are positioned 
in beside-ness rather than beyond-ness. Such a positionality re-configures the structure of the binary, which is a configuration that permeates much of the critical theorizing that emerges from teleological or totalizational frameworks. Through affect theory, the binary is bifurcated, distorted, contorted; this form of re-configuration enables an alternative "special way of thinking about the world" ${ }^{38}$. I have focused on affect's distorting the binary of interiority/exteriority, thereby enabling a reimagining of subjectivity via alternative conceptualizations of the roles of touch and sovereignty. In doing so, I hope to have given an adequate example of what an alternative mode of attending might look like for critical theorizing in social and political thought. Attending alternatively is thus not about making a move 'outside' pre-existing or predominant frameworks of knowledge production, but rather about finding an 'outside' that already resides within — by setting our sights differently.

Let us close off with a note on the ethics of attending. What would an ethics of attending entail? Given the scope of the present paper, we must acknowledge that we are accountable to the ways in which we intend to attend in our endeavours of knowledge production. With this in mind, we must ask ourselves how it is that we choose what to attend to, and how to attend, when we know that our choices will inherently exclude certain forms of knowledge production; we must ask ourselves what ways of looking at the world our theoretical attentive stances enable, and what other many ways they simultaneously disable. As such, we must own up to the intentionality involved in attention, in the engagement of our will to 'see' certain things, while making ourselves blind to others. We must harness the awareness that, in the willful act of attending, we make accessible certain forms of knowledge to ourselves and the academic communities in which we are engaged, while making others inaccessible. We must then engage deeply with the question: How does attending to the possibilities — and, perhaps more importantly, the limitations - of attention make us re-think our relationship to epistemology and methodology?

\section{Notes}

1. Wayne Wu, Attention (New York, NY: Routledge, 2014), 9.

2. William James, The Principles of Psychology (New York, NY: Henry Holt and Company, 1890), 403, quoted in Wayne Wu, Attention (New York, NY: Routledge, 2014), 3-4.

3. Wayne Wu, Attention (New York, NY: Routledge, 2014), 270 (emphasis added).

4. Ibid., 139 (emphasis added).

5. Ibid., 222 (emphasis added).

6. Melissa Gregg and Gregory J. Seigworth, eds., The Affect Theory Reader (Durham, NC: 
Duke University Press, 2010), 2 (emphasis added).

7. Eve Kosofsky Sedgwick, Touching Feeling: Affect, Pedagogy, Performativity (Durham, NC: Duke University Press Books, 2013), 1.

8. Ibid. (emphasis added).

9. Ibid.

10. Ibid.

11. Ibid.

12. Ibid., 8 (emphasis in original).

13. Kathleen Stewart, Ordinary Affects (Durham, NC: Duke University Press Books, 2007), 6 (emphasis added).

14. Ibid., 7.

15. Ibid. (emphasis added).

16. Judith Butler, Senses of the Subject (New York, NY: Fordham University Press, 2015), 1 (emphasis added).

$\begin{array}{ll}\bar{n} & 17 . \text { Ibid., } 6 . \\ \frac{\hat{\sigma}}{a} & 18 . \text { Ibid., } 2 . \\ 10 & 19 . \text { Ibid. }\end{array}$

20. Ibid., 8 .

21. Ibid., 12 .

22. Ibid., 9.

23. Ibid.

24. Ibid.

25. Ibid., 8 .

26. Isabell Lorey, State of Insecurity: Government of the Precarious (Brooklyn, NY: Verso Books, 2015), ix (emphasis added).

27. Ibid.

28. Ibid., $\mathrm{x}$ (emphasis added).

29. Ibid., 10 .

30. Ibid., 18. 
31. Ibid., 19 (emphasis in original).

32. Ibid. (emphasis added).

33. Ibid. (emphasis added).

34. Ibid., 99.

35. Ibid., 101-102 (emphasis added).

36. Ibid.

37. Elizabeth Grosz, Space, Time, and Perversion: Essays on the Politics of Bodies (New York, NY: Routledge, 1995), 133.

38. Wayne Wu, Attention (New York, NY: Routledge, 2014), 222.

\section{Bibliography}

Butler, Judith. 2015. Senses of the Subject. New York, NY: Fordham University Press.

Gregg, Melissa, and Gregory J. Seigworth, eds. 2010. The Affect Theory Reader. Durham, NC: Duke University Press.

Grosz, Elizabeth. 1995. Space, Time, and Perversion: Essays on the Politics of Bodies. New York, NY: Routledge.

Lorey, Isabell. 2015. State of Insecurity: Government of the Precarious. Brooklyn, NY: Verso Books.

Sedgwick, Eve Kosofsky. 2013. Touching Feeling: Affect, Pedagogy, Performativity. Durham, NC: Duke University Press Books.

Stewart, Kathleen. 2007. Ordinary Affects. Durham, NC: Duke University Press Books. Wu, Wayne. 2014. Attention. New York, NY: Routledge. 